\title{
The Analysis of the Present Situation and Countermeasures of College Scientific Research Fund Management
}

\author{
Dong-sheng Huang, Wei-xing Yao \\ Donghua University, Songjiang, Shanghai, China
}

\begin{abstract}
According to a lot of irregularities in the management of scientific research funds in China, this paper presents the core in the management of scientific research funds is to focus on design of the funds management operation mechanism. It is possible to improve the use of funds efficiency and reduce the unnecessary risks in the use of funds through the establishment of information communication mechanism, the corresponding budget management mechanism, cost accounting mechanism and supervision mechanism of management to the scientific and rational use of scientific research funds.
\end{abstract}

Keywords - College, scientific research fund management, problems, countermeasures

\section{高校科研经费管理现状分析及应对措施}

\author{
黄东生 姚卫新 \\ 东华大学, 松江, 上海, 中国
}

\begin{abstract}
摘 要 本文针对近年来我国科研经费管理中出现了很多违规问题, 提出高校科研经费管理的重心应着重于经费管理机制的设计 运行, 通过建立相应的信息沟通机制、预算管理机制、成本核算机制及监督管理机制来科学、合理的使用科研经费, 提高经费使用效 益, 降低经费使用中不必要的风险。
\end{abstract}

关键词 高校, 科研管理, 问题, 措施

\section{1. 引言}

进入 21 世纪以来, 国家大力提倡增强国家的自主创新 能力, 推出了建设创新型国家的重大战略决策。高等院校 作为国家科学研究的主力军, 在科学研究方面发挥着排头 兵和先锋的作用, 因此承担了较多的科研项目。然而, 由 于各高校科研经费监管力度和管理制度的不完善, 近年来 我国科研经费管理中出现了很多违规现象, 而且越来越严 重, 这就使得对规范合理使用科研经费的监管需求变得越 来越迫切。本文结合工作实践, 针对科研项目经费申请、 使用、监督管理过程中存在的问题, 提出通过建立相应的 信息沟通机制、预算管理机制、成本核算机制及监督管理 机制来科学、合理的使用科研经费, 提高经费使用效益, 降低经费使用中不必要的风险。

\section{2. 高校科研经费管理中的主要问题}

\section{1 经费申请中的问题}

（1）经费申请信息不对称

高校科研经费的申请由于缺少透明度, 造成科研项目 人员的科研能力水平与其获得的经费配置严重的不对称。 按照一般规律, 科研项目人员的科研能力水平越高, 其获 得的科研经费也越多, 两者呈正比。但是实际情况却不一 定, 这是由于科研项目申请人员社会活动能力的高低往往 在项目经费配置和获取时占有很重要的因素, 因此导致实 际科研水平相对较低而公关和社会活动能力相对较强的人 员获得经费的可能性更高一些。另外, 我国高校科研项目 经费申请情况还有一个怪现象, 科研项目人员获得经费的 能力往往是由项目申请者的职务和社会地位所决定而不是 由其学术研究能力所决定, 因此, 往往作为一个领导获得 
项目的可能性更大或者获得配置的经费金额更高。

(2) 预算编制不准确

高校目前科研项目经费预算编制仍然由项目申报人员 独立完成, 缺乏财务人员的参与, 未能实现科研人员与财 务人员的结合, 影响了项目经费预算编制的预见性和准确 性, 不仅影响项目申报, 还影响预算的执行以及最后的财 务验收。高校的在科研项目实际研究过程中, 大部分科研 项目的负责人往往还会同时承担多个课题项目的研究, 而 这些项目之间往往也存在着一定的关联性或者项目之间有 交叉部分, 正常情况下, 部分项目的设备、实验仪器以及 相关资料应该可以互相利用; 而实际情况往往是只要新申 请一个项目, 在预算申报时就申请购买新的设备或材料, 这就出现了项目经费的严重浪费现象, 而在经费结算时, 也会导致经费出现大量结余的现象, 影响项目结题的验收。

\section{2 经费使用中的问题}

\section{（1）经费支出核算不严格}

科研经费支出的规范性是指研究发生的项目经费支出 应符合合同或者预算批复的要求, 科研经费支出应与项目 工作开展相关; 对于需超预算、超范围支出执行的须先行 履行预算调整报批或报备手续, 且预算的调整符合经济性、 合理性、相关性要求。但是科研经费在实际支出时却与项 目的相关性不强, 费用的支出与研究工作没有直接的联系, 或者预算没有安排而实际发生费用并列入了支出等等。

（2）经费报销中出现违规、违纪现象

虽然高校建立了科研经费管理制度, 并规范了报销流 程, 但是对于科研项目经费违规使用的现象在高校仍然时 有发生。个别科研项目人员为了谋取私人利益, 将不正当 的个人消费支出用于科研项目经费。财务人员虽然根据科 研项目管理制度, 审核了票据的真实性和相关手续的完整 性, 但是并不能合理控制经费使用途径是否正当, 这就导 致经费滥报虚报的现象时有发生。

\section{（3）经费成本核算不健全}

全成本核算是指全面反映核算对象所有的直接和间接 成本, 而高校对于科研项目延用提取一定比例管理费的做 法, 提取所得用于弥补高校的项目管理支出, 对于科研项 目占用教学资源、科研人员薪酬、水电费、实验室折旧和 设备折旧等未作补偿要求, 没有建立对于科研物料统一的 监管机制, 不能真实地反映所承担科研项目的全部成本, 导致项目经费结余增加, 不利于项目经费使用与管理绩效 评价的开展。

\section{3 经费监督管理中的问题}

（1）经费管理制度不健全

高校的科研经费在具体报销流程和管理制度上因各种 原因时常会发生变化, 但往往又缺乏一定的宣传, 导致科 研人员不能及时掌握相关流程和政策, 时常发生抱怨。再 由于各财务人员对制度的理解和掌握程度的各不相同, 往 往也为科研人员在经费报销时造成很大的困扰, 经常会出 现同一项目经费同一性质的报销今天可以报销而下一次又 不能报销的现象。这样就造成财务人员和科研人员之间产 生了严重矛盾, 科研人员往往认为财务人员工作具有随意 性或者故意进行刀难, 其实是由于客观原因造成, 但事实 这种现象往往会严重影响科研经费使用人员的积极性, 认 为科研项目申报难, 使用则更难, 这固然是由于财务人员 自身工作的原因, 也有相当程度是由于科研人员对经费使 用规则的不了解。

\section{（2）经费管理与项目管理脱节}

科研项目经费在预算编制阶段, 科研管理部门、财务 部门和项目组缺少沟通协作, 因此不能有效制定预算编制 工作。而高校的大部分科研人员都是专业的学术人才, 并 不具备财务管理方面的专业知识, 更不懂得预算编制理论 及方法, 对财务管理方法缺少认知, 这就造成在预算编制 阶段, 只是根据以往的经验作为预算的测算依据, 造成预 算随意性强, 内容不够全面。部分项目人员为了提高项目 申请的成功率, 编制的项目预算往往还偏离了项目的实际 需求。

\section{（3）经费执行缓慢}

科研项目经费使用人员往往不按照项目申请时的进度 进行科研经费的支出, 有时甚至刻意的造成科研经费的结 余, 这就造成科研经费执行缓慢形成结余, 使得该利用的 经费得不到合理利用。

\section{（4）经费监督机制不完善}

高校没有建立对科研经费全过程的审计制度, 缺乏对 经费支出的实时监控; 缺乏审计规范, 难以做出合理的审 计决定; 缺乏严格的立项跟踪及结题审计, 审计部门没有 充分发挥其事前、事中和事后监督职能, 不能及时发现经 费开支的漏洞、纠正科研预算不合理、开支随意性大以及 科研经费大量结余等问题; 缺乏问责机制, 审计结论没有 对各项目组科研经费的使用管理起到应有的警示作用。

（5）激励机制不完善

当前, 我国高校的工资计算当前主要还是依据教职工 的工龄、职称等进行计算, 这就无法体现出科研工作人员 实际的工作量, 以及对国家科技作出的贡献。因此广大教 
师承接项目的动机往往是为了晋升职称等, 导致参加科研 项目的积极性不高。承担的科研项目付出的巨大劳动得不 到期望的奖励, 也会导致科研项目人员往往采用虚报等方 式套取科研经费, 作为自己的回报。这就直接导致了经费 不能得到合理的应用, 变相的缩减了经费开支, 直接影响 科研成果。

\section{3. 解决科研经费管理问题的应对措施}

针对高校科研经费管理中的主要问题, 我们从加强科 研预算编制、完善科研经费管理制度、建立有效的信息沟 通机制、推进科研经费全成本核算及完善科研经费绩效评 价机制等方面进行改进, 确保科研经费使用的科学化、规 范化、合理化。

\section{1 加强预算编制工作}

项目组要切实负起制订项目预算的责任, 联同高校财 务部门, 科学制订项目预算。预算应包括与科研计划相匹 配的经费收入预算和经费支出预算, 应当合理、充分地估 计各项可能发生的费用支出, 按照申报要求, 合理确定劳 务费、会议费、出国考察费、设备购买费用、会议支出和 管理费等比例, 尽可能大地保留实验材料费、测试化验费、 燃料动力费和出版文献费等科研直接费用的比例, 并尽可 能地开展经费负担能力评估、科研资产发展预估以及科研 风险负责能力预估。

此外还必须建立起预算跟踪反馈机制, 掌握预算的执 行情况, 生成各类反馈分析报告, 以便对预算执行过程进 行全面的监督和控制, 对预算进行调整, 对结题时进行预 算的效果考核。

\section{2 明确科研经费管理机构职责}

科学的组织分工管理是做好高校科研经费管理的保证 和必要条件, 为了保证科研项目的顺利实施, 必须明确科 研经费管理的工作程序及其步骤, 明确有关项目管理部门 和项目承担单位在科研经费管理中的权力和职责, 全面提 升管理效率。高校应该理顺科研管理部门、经费管理部门、 课题组三者的关系, 保证科研工作的顺便进行。高校科研 管理部门、财务处、项目负责人要各负其责, 不但要做好 本职能范围内的工作, 还要加强联系, 密切配合, 共同做 好科研经费的管理工作。科研处应该协同财务预算处搞清 经费来源及其特点, 对不同来源和特点的科研经费采取不 同的管理策略; 财务处应该协同科研处做好项目管理工作, 完善科研经费管理制度, 坚持既要方便科学研究工作, 又 要严肃财经纪律的原则; 项目负责人应该积极配合科研管
理部门和财务部门的工作, 强化科研风险意识, 严格按照 预算计划执行费用开支, 加强与科研管理部门和财务部门 的沟通, 保障科研项目有序的进行。

\section{3 完善科研经费管理制度}

加强科研经费管理制度建设, 应从完善科研项目经费 管理办法, 健全项目核算制度、加强项目合同管理、规范 项目管理流程等方面实施。高校科研管理合同制是我国科 研管理适应新的经济体制的一项重大改革, 要加强对科研 经费使用情况监督, 根据合同要求进行跟踪管理。高校科 研管理人员要积极参与这项工作中去, 要负责对科研合同 的谈判、签订、监督和管理。签订科研合同后一般高校科 研项目就是实行项目组长负责制, 为确保科研经费专款专 用, 避免挪用于项目外的其他开支, 提高科研经费的使用 率, 项目经费拨入高校后, 科研管理部门要加强对项目负 责人的教育与培训工作, 使项目负责人懂得如何规范、高 效地使用好科研经费。

\section{4 建立有效的信息沟通机制}

在完善科研经费管理机制的过程中尤其要建立信息沟 通机制, 充分的信息沟通可以解决各方的信息不对称问题。 高校应通过科研网络管理平台, 形成对项目活动各个环节 的全面管理, 采用工作流的思想建立起项目管理信息系统, 方便各科研单位、科研管理部门、财务部门、资产部门等 进行业务协同, 提高各项目审批的效率。对各工作流程实 施严格的监督和控制, 利用科研项目信息管理平台, 可实 现对科研项目信息的发布, 有利于信息公开程度的提高。 通过该平台, 充分发挥网络通讯技术的效果, 实现各部门、 高校、社会及科研人员之间的信息交流。科研管理平台可 集成高校的网络教学、科研资源, 从而达到科研资源的充 分共享。

\section{5 推进科研经费全成本核算}

按照国家科技部等四部委联合颁布的关于国家科研计 划实施课题制管理的规定要求, 课题经费应该实行全额预 算管理, 建立健全经费支出预算体系、合理编制和严格执 行课题研究经费支出预算, 加强课题成本核算, 加强课题 结余经费的管理。高校执行经费全成本核算应当区分直接 成本与间接成本，同时需要将人员费纳入课题经费预算、 加强对科研物料的监控以及要全面计算和结算间接费用 等。 


\section{6 完善科研经费绩效评价机制}

对科研经费使用情况开展绩效考核工作, 建立和完善 追踪问责制度，充分挖掘资金潜力, 努力提升资金使用效 益, 从而提高科研活动的实际经济效益。其中开展科研项 目经费的绩效审计就是非常有效的途径, 在审计评价过程 中, 应采用定量与定性相结合的方法, 并以定性分析为主。 通过定量分析, 测算预算执行进度和支出结构并得出相关 结论; 通过定性分析, 判断项目经费开支是否专款专用, 是否具有相关性、经济性和合理性。

总之, 对于高校科研经费的管理, 高校首先应强化科 研经费管理的风险防范意识, 在组织结构和管理体制上对 科研经费管理形成保障, 并加强管理人员和科研人员的培 训, 提高人员综合素质; 同时, 从更长远的角度考虑, 需 发掘问题产生的根源和剖析原因, 健全和规范科研经费管 理体制机制。科研经费管理机制的完善, 是保障科研经费 有效管理的关键。此外，还应完善高校内部收入分配制度， 制定科研成果转化奖励政策, 鼓励提高科研经费的产出效 益。

\section{参考文献(References)}

[1] Ministry of Education. Opinions on further strengthening the management of university scientific research project (Jiaoji [2012] No. 14). 2012-12-18.

[2] Ministry of Finance, Ministry of Science and Technology. The notice of provisions concerning the adjustment of national science and technology plan and nonprofit industry research special funds management approach (Caijiao [2011] No.434). 2011-9-14.

[3] Shao Jirong, Zheng Huifen. The status and countermeasures of the college scientific research fund management. Education of accounting research, 2012, (2).

[4] Zhan Yiqing, Ouyang Hua, Liu Aidong. American University research project funded by the government of indirect cost policy studies at the. Research and development management, 2009, (6).

[5] Zhu Yukun. The problems and countermeasures of university scientific research project funds management. Value engineering, 2011, (30): 226-227. 